\title{
Fatigue Fractures of the Sacrum on Children: Case Report
}

\begin{abstract}
Fatigue fractures of the sacrum in children are very rare and the diagnosis is often delayed or incorrect. The authors report the case of a healthy 10-year-old child, active soccer player, presented with a ten days' history of insidious onset of his mechanical low back pain without any history of trauma. Plain radiography of the lumbosacra spine and pelvis was also normal. The MRI showed images which were consistent with a stress fracture. It is of paramount importance to make a prompt and accurate diagnosis of a fatigue fracture so as to avoid unnecessary invasive investigations.
\end{abstract}

\section{Introduction}

Currently, fatigue fractures of the sacrum in children are very rare and the cases published in the literature are few. The incidence among athletes is estimated to be from $2 \%$ to $4 \%$ and although its incidence in children is unknown, we predict a lot of cases remain under-diagnosed [1]. Sacral stress fractures are usually classified as insufficiency or fatigue fractures, as described by Pentecost $\mathrm{R}$ et al. [2]. Insufficiency fractures are the result of a normal stress under a weakened bone, whereas a fatigue fracture occurs after abnormal or repetitive stress of a normal elastic and resistant bone. Insufficiency fractures affect mostly elderly people who have undergone radiotherapy or suffer from osteoporosis, rheumatoid arthritis, fibrous dysplasia and metabolic bone diseases. Conversely, fatigue fractures occur mostly on young people, especially athletes who practice long-distance running, or gymnastics. According to Denis $\mathrm{F}$ et al. classification of sacral fractures, there are three different zones in the sacrum where the fracture can occur [3]. The first zone corresponds to sacral wings, the second zone to sacral foramina and the third zone to body and canal of sacrum. Usually only the second and third zones fractures have neurologic symptoms. However, the majority of sacral stress fractures occur in the first zone, but they rarely produce neurologic symptoms.

The sacrum is the keystone in the arch of the pelvis and large stresses pass through it into the innominate bones, causing a stress fracture [4]. The sacrum, like every bone in the pelvis and in the lower limb, bears body weight and may be susceptible to stress fractures [5]. Some studies suggest these fractures appear after increasing the intensity of an activity or altering the manner in which a given activity is performed [6]. The diagnosis is often delayed or mistaken as there is limited awareness of this condition, leading physicians to perform unnecessary or even harmful exams. The purpose of this case report is to remind clinicians that sacral fatigue fractures must be considered as a differential diagnosis of low back pain in children. Such a diagnosis usually requires a high index of suspicion, because physical findings are not exuberant and plain radiographic findings are typically normal $[5,7]$.

\section{Case Report}

The authors report the case of a healthy 10-year-old boy, active soccer player, presented with a ten days' history of insidious onset of

\section{Journal of \\ Orthopedics \& Rheumatology}

\section{Rafael Portela* and Mafalda Santos}

Centro Hospitalar Vila Nova de Gaia / Espinho, Portugal

*Address for Correspondence

Rafael Portela, Centro Hospitalar Vila Nova de Gaia / Espinho, Portugal, Tel: +351924442990; E-mail: RafaelPortelaSilva@gmail.com

Submission: 06 November, 2017

Accepted: 21 November, 2017

Published: 28 November, 2017

Copyright: (๑) 2017 Portela R. This is an open access article distributed under the Creative Commons Attribution License, which permits unrestricted use, distribution, and reproduction in any medium, provided the original work is properly cited.

his mechanical low back pain, without any history of trauma. Pain was exacerbated by activity and relieved with rest. There was no history of fever or other complaints. No neurologic impairment was experienced. His past medical history was unremarkable. Physical examination disclosed tenderness in the right buttock over the sacroiliac joint and limping. Full haematological, biochemical and inflammatory profiles were entirely normal.

The anteroposterior and lateral plain radiographs of the lumbosacral spine and pelvis was normal. Magnetic resonance image of the lumbar spine, sacrum, and pelvis showed no evidence of a soft tissue mass, lumbar disc or vertebral pathology and infectious process. However, T1 and T2 weighted images showed areas of low and high signal changes in the medullary region of the right sacral wing surrounding a central linear very low signal void of which were consistent with a stress fracture (Figures 1 and 2).

It was recommended a four weeks cessation of heavy physical

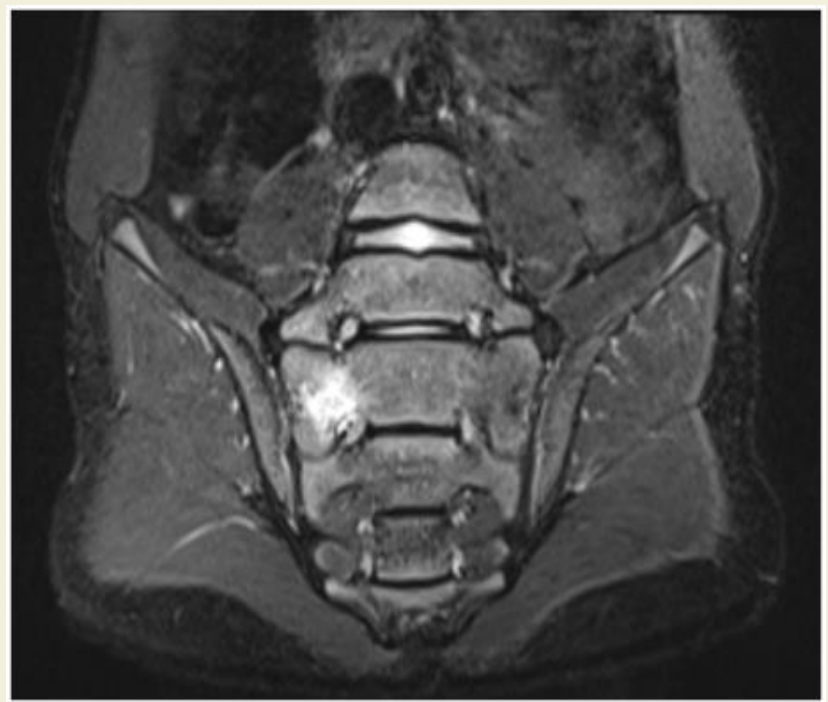

Figure 1: MRI image consistent with a stress fracture. 


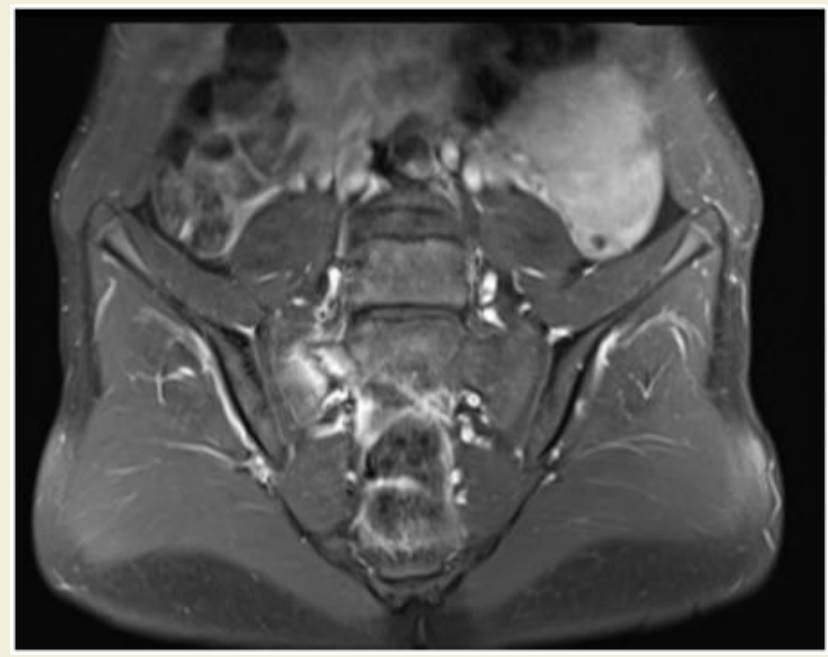

Figure 2: MRI image consistent with a stress fracture.

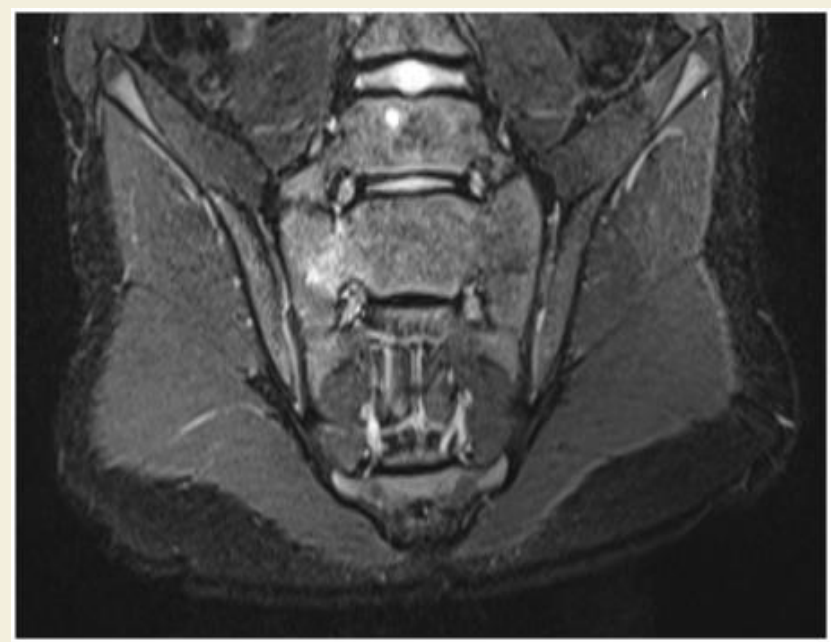

Figure 3: MRI showing healing fracture.

activities. However, against medical advice, he continued to go to school and to perform daily-life activities, although he stopped to play soccer.

After 6 weeks, his symptoms settled over and he was allowed to gradually perform his normal activities. A second MRI was performed, which confirmed a healing fracture (Figure 3). After 1 year of follow up the patient remained asymptomatic without, any limitation or pain on sports or daily life activities.

\section{Discussion}

Fatigue fractures of the sacrum in children are particularly uncommon and only few cases have been published [8-13]. Although sacral insufficiency fractures are more common and better documented fatigue fractures have been increasingly reported among males, females, that practice different types of sports like tennis, basketball and soccer $[1,14-16]$. It also has been associated with military recruits, pregnant and post-pregnancy women [17].
Usually there isn't a history of preceding trauma and the clinical presentation is low back pain and buttock tenderness. Due to the weight bearing function of the sacrum, the pain intensifies with physical activities and reduces with rest. Generally, they are not associated with any kind of any neurologic impairment. Biologic results are usually normal [8-10].

Conventional radiographies are usually normal as in our case report. Because of their relatively low cost and easy access, X-rays remain the first image diagnostic examination. Consequently, a high index of clinical suspicion is required to make the diagnosis of sacral stress fracture in a child [9]. Typically, these patients are practitioners of sport, and they report unilateral low back pain that aggravates with weight load bearing, sometimes after a period of increased training intensity, without any other symptoms or signs.

Advanced imaging diagnostic exams are required for correct diagnosis, like Computed tomography (CT), bone scintigraphy or Magnetic resonance imaging (MRI). Supported by the literature we only performed MRI and it was of great value to make a prompt diagnosis $[9,10,13,18]$. MRI picks up signal from bone marrow oedema, consequence of fracture-inflammation and reparation process. Bone scintigraphy and CT can also be used as diagnostic tools, mainly as an alternative to MRI. However, MRI is the most sensitive exam and should be performed when malignancy or infection are a concern [19].

Sacral stress fractures are usually stable and the treatment is based on cessation of physical activities for 4 weeks and pain control with analgesics $[3,20,21]$. After complete symptom resolution, the patient can return to normal physical activities. In this case report, our patient didn't do a full cessation of activities, but has stopped playing soccer, which was enough for his symptoms to cease. Twelve months after diagnosis, there was no sign of residual pain or other sequelae.

Fatigue fracture of the sacrum in a child make differential diagnosis with a wide range of pathologies like sacroiliitis, pars interarticularis fracture and osteoid osteoma [8]. Of great importance is the possibility of a bone infection or a soft tissue malignancy, which highlights the value of a correct and quick diagnosis.

\section{Conclusion}

To conclude, stress fractures of the sacrum have a good prognosis and because they can mimic infection and primary bone malignancy, it is of paramount importance to make a prompt and accurate diagnosis so as to avoid unnecessary invasive investigations. To the best of our knowledge, this is the first reported case of a fatigue sacral fracture in a child soccer player [1].

\section{References}

1. Tzoanos G, Tsavalas N, Manidakis N, Karantanas A (2013) Sacral fatigue fracture in an amateur soccer player. Case Rep Med 2013: 985310.

2. Pentecost RL, Murray RA, Brindley HH (1964) Fatigue, insufficiency, and pathologic fractures. JAMA, 187: 1001-1004.

3. Denis F, Davis S, Comfort T (1988) Sacral fractures: an important problem. Retrospective analysis of 236 cases. Clin Orthop Relat Res 227: 67-81.

4. Reno JH (1959) Athletic injuries of the pelvis, hip and thigh. Am J Surg 98: 451-456. 
5. Micheli L, Curtis C (2006) Stress fractures in the spine and sacrum. Clin Sports Med 25: 75-88.

6. Fredericson M, Salamancha L, Beaulieu C (2003) Sacral stress fractures Phys Sportsmed 31: 31-42.

7. Blake SP, Connors AM (2004) Sacral insufficiency fracture. Br J Radiol 77 891-896.

8. Lam KS, Moulton A (2001) Stress fracture of the sacrum in a child. Ann Rheum Dis 60: 87-88.

9. Grier D, Wardell S, Sarwark J, Poznanski AK (1993) Fatigue fractures of the sacrum in children: two case reports and a review of the literature. Skeletal Radiol 22: 515-518.

10. Rajah R, Davies AM, Carter SR (1993) Fatigue fracture of the sacrum in a child. Pediatr Radiol 23: 145-146.

11. Haasbeek JF, Green NE (1994) Adolescent stress fractures of the sacrum: two case reports. J Pediatr Orthop 14: 336-338.

12. Volpin G, Milgrom C, Goldsher D, Stein H (1989) Stress fractures of the sacrum following strenuous activity. Clin Orthop Relat Res: 184-188.
13. Coursier R, Degisors S, Lespessailles E, Toumi H (2015) Sacral ala stress fracture in a child. J Clin Case Rep 5: 1-2.

14. Iwamoto J, Takeda T (2003) Stress fractures in athletes: review of 196 cases. J Orthop Sci 8: 273-278.

15. Shah MK, Stewart GW (2002) Sacral stress fractures: an unusual cause of low back pain in an athlete. Spine (Phila Pa 1976) 27: E104-E108.

16. Silva RT, De Bortoli A, Laurino CF, Abdalla RJ, Cohen M (2006). Sacra stress fracture: an unusual cause of low back pain in an amateur tennis player. Br J Sports Med 40: 460-461.

17. Lin JT, Lutz GE (2004) Postpartum sacral fracture presenting as lumbar radiculopathy: a case report. Arch Phys Med Rehabil 85: 1358-1361.

18. Tsiridis E, Upadhyay N, Giannoudis PV (2006) Sacral insufficiency fractures: current concepts of management. Osteoporos Int 17: 1716-1725.

19. Lyders EM, Whitlow CT, Baker MD, Morris PP (2009) Imaging and treatment of sacral insufficiency fractures. AJNR Am J Neuroradiol 31: 201-210.

20. Li M, Xu RM (2011) Diagnosis and treatment of occult sacral fractures. Zhongguo Gu Shang 24: 1051-1054.

21. Hosey RG, Fernandez MM, Johnson DL (2008) Evaluation and management of stress fractures of the pelvis and sacrum. Orthopedics 31: 383-385. 